\title{
The Revival of Local Authority Mutual Insurers in the U.K.
}

\author{
John Hood, Bill Stein and Jim McKendrick
}

Division of Accountancy, Finance and Risk, Glasgow Caledonian University, City Campus, 70 Cowcaddens Rd, Glasgow G4 0BA, U.K.

E-mail: j.hood@gcal.ac.uk

This paper discusses recent attempts by U.K. local authorities to create mutual insurance companies. We explore in general terms the background to mutuals (or pools) in the U.K. public sector. We consider two specific and recent cases in order to tease out the key issues: a rejected feasibility study undertaken by a number of Scottish local authorities and a mutual formed by a consortium of London local authorities, the London Authorities Mutual Limited. Our analysis and comparison indicates that for some local authorities there remain a number of barriers to this form of innovation in risk financing. We conclude that while mutuals are not a panacea for local authority risk financing problems, they are an alternative worth exploring.

The Geneva Papers (2009) 34, 271-286. doi:10.1057/gpp.2009.3

Keywords: local authorities; risk pooling; mutual insurance

\section{Introduction}

Key developments in the public sectors of many countries over the past two decades have been the notion of "modernisation", generally meaning a shift from a traditional public sector ethos to a more private sector approach, and its corollary "innovation". 1 Innovation was, in the past, anathema to many in the public sector as by its very nature it introduced risk into what was a risk-averse environment. For example, in the U.K., central government does not wish to see other parts of the public sector taking excessive risk, or taking risks which may be acceptable in the private sector but are regarded as being outside the public domain. The mantra is one of "balanced" or "well managed" risk taking. How, therefore, can public bodies construct a system to fully exploit private sector knowledge of the possibilities for the management of risk, especially for the financing of risk, yet comply with rules and regulations relating to the risks they are allowed to take?

U.K. local authorities, as a significant part of the wider public sector, have traditionally been both limited and cautious in their choice of mechanisms for financing the complex set of risks that they face, especially those which are insurable. ${ }^{2}$ In reality, the financing mechanism of choice for insurable risks has been the purchase of commercially available insurance cover, often by means of an "insurance

\footnotetext{
${ }^{1}$ Bovaird and Löffler (2003); Flynn (2007).

${ }^{2}$ Hood and Young (2005); Fone and Young (2005); ALARM (2005).
} 
fund". 3 The utilisation of insurance would square with the lower rung of "Stewart's ladder", 4 which is concerned with different levels of accountability within, especially public, organisations, whereby those accountable for financing risk could, by sanctioning the purchase of insurance, satisfy criteria on legality and probity. Yet, as this paper will explain, although still highly significant as a mechanism to treat risks, traditional insurance is not without its weaknesses. For U.K. local authorities, the existence of rules, regulations and constraints imposed by central government has created barriers to the use of innovative alternatives to insurance. By contrast, many large private sector organisations have not been subject to the same fiscal and regulatory regimes and, as a consequence, have experimented with a range of risk financing methods. Not all of these methods have been successful and some of them remain inappropriate for local authorities. Detailed analysis of the applicability of alternative risk financing mechanisms for local authorities has been an under-researched area, and this paper addresses this knowledge gap. Specifically, we investigate the risk financing method known as mutuals, or pooling. The legislative landscape for U.K. local authorities has changed and the possibility opened up that risk pooling may no longer be dismissed as ultra vires, that is beyond the powers granted to them. The topic has attracted much recent interest with the creation of the London Authorities Mutual Limited (LAML), a risk pool formed by a number of London Boroughs, the City Corporation of London and the Greater London Authority. Fire and Rescue Mutual (FRAML) was launched and plans also announced for the creation of the Councils Alternative Risk \& Insurance Group (CARIG). Against the background of these developments we examine in detail a proposal for a pool of Scottish local authorities which was rejected following a feasibility study and we compare this with the LAML case. This paper is intended to provide a useful addition to the available literature that will inform the debate over the use of mutuals and pools by local authorities.

\section{History of U.K. local authority insurance purchasing}

The case for and against heavy reliance on insurance by any organisation has been well covered in the literature. ${ }^{5}$ Until 1992, however, U.K. local authorities relied almost exclusively on the Municipal Mutual Insurance (MMI) to provide coverage against the vast majority of their insurable risks. The MMI had been in existence since 1903, and by the 1970 s it was providing insurance to over 90 per cent of U.K. local authorities. ${ }^{6}$ Owing to a number of different factors including increased claims, a flawed diversification strategy and the constraints of mutuality in raising capital, the MMI collapsed in 1992 and the staff and renewal rights were absorbed into the Zurich Insurance Group to become Zurich Municipal Insurance (ZMI). After MMI's demise, an apparently adequate, albeit restricted, commercial market emerged which itself was affected by a downturn in the underwriting cycle, a significant decline in investment

\footnotetext{
3 LASAAC (2005).

${ }^{4}$ Stewart (1984).

${ }^{5}$ See for example Nawaz and Stein (1998); Punter (2002); De Mey (2003).

${ }^{6}$ Fone and Young (2005).
} 
returns, and a number of other problems, such as terrorism concerns, which all converged in late 2001. Hood and Acc-Nikmehr ${ }^{7}$ discuss how this insurance crisis impacted on a form of insurance which is particularly relevant to U.K. local authorities, that is Employers' Liability (EL) cover. EL cover is compulsory in the U.K. and, although local authorities are theoretically exempt from compulsion, in practice most, if not all, purchase this cover. As local authorities are, collectively, the largest employers in the country, any dislocation in the commercial insurance market presents them with significant difficulties.

A number of commentators ${ }^{8}$ have questioned the rationale for insurance being such a central plank of local authority risk financing strategy and practice. They have raised the question of over-reliance on commercially purchased insurance being a potentially flawed strategy and have explored a number of issues surrounding both the insurance market and variations on the basic theme of insurance.

Although, like all public sector organisations, local authorities have been under increasing pressure to be more "business-like", it is often unclear what being "business-like" really entails. Christopher Hood" in his seminal exposition of "New Public Management" identifies one of its "doctrinal components" as the adoption of a "private sector" management style. In the context of risk financing this could, arguably, point to a more challenging attitude to the status quo and a greater exploration of the alternatives to insurance which have been developed over the past 20 years or so. The reality, at least in the U.K., however, is that despite some convergence between private and public management techniques, local authorities have substantially eschewed the alternative risk financing techniques which the private sector have embraced. It should be recognised, therefore, that conventional insurance may fit well with the risk appetite of local authorities. In addition to this cautious approach, it must always be borne in mind that there are constraints on the activities of local authorities which do not apply to private sector organisations. In effect, authorities have traditionally only been able to act in accordance with very specific powers given to them by central government and have not had the freedoms and flexibilities found in the private sector.

Notwithstanding all of these factors, and given the case against conventional insurance, there is a sustainable argument that local authorities should, at least, explore the feasibility and viability of those alternatives which are intra vires, that is, within their powers. As will be discussed, risk pooling appears to meet this criterion though this is currently being tested in the Courts.

The main body of this paper divides into three sections. Firstly, we examine the long-established use of risk pooling, how pools differ from traditional insurance, and how market- and government-led developments have caused them to have renewed relevance to local authorities today. Secondly, we set out a detailed description of the feasibility study conducted by 16 Scottish local authorities and we consider the development of the LAML and the current legal challenge to its

\footnotetext{
${ }^{7}$ Hood and Acc-Nikmehr (2006).

${ }^{8}$ Gollier and Pratt (1996); Gollier (2001, 2003); ALARM (2005).

${ }^{9}$ Hood (1991).
} 
very existence. Finally, subsequent discussion centres on the similarity of the issues revealed by both cases.

\section{Risk pooling}

The specific issue of local authority risk mutuals or pools has not been explicitly addressed by U.K. central government, but it is interesting to note that the department which is seen as being the "head office" of central government, the Cabinet Office, has produced a report, ${ }^{10}$ containing material relevant to local authorities which is clear on the related, wider issue of risk financing in its statement: "We recommend that the Treasury should consider running a pilot of the use of captive insurance arrangements in government".

Given central government's "Modernisation" agenda and the inherent problems of the conventional insurance market, it seems strange that there has been, until only very recently, little movement among local authorities towards risk pooling, although there is some evidence of increased interest. ${ }^{11}$

Risk pooling, at a basic level, is an example of local authorities cooperating in an exercise in risk spreading and taking advantage of economies of scale. To a certain degree, precedents for this exist in the well-understood ideas of consortium purchasing and the National Procurement Strategy. ${ }^{12}$ In reality, however, risk pooling is more complex than authorities simply cooperating in the purchase of services and capital equipment and it raises issues of risk and liability sharing. As our Scottish case study will demonstrate, there may also be concerns in local authorities over how pooling can, in the short term, satisfy central government requirements on Best Value in a competitive environment where commercial insurers may offer reduced premiums to retain business. Despite these difficulties it is, however, a valid, feasible and highly relevant alternative to traditional insurance procurement which is worthy of exploration.

On a global basis, public sector risk financing mutuals or pools are not new, with some government pools in, for example, Japan having their origins in the 1920s and earlier. ${ }^{13}$ Although there appears to be no publicly accessible European database, there is sufficient evidence that the local government mutual concept has been grasped in a number of countries, examples being Ethias in Belgium and S:t Erik Försäkring in Sweden. In addition, enquiries with the Association of Mutual Insurers and Insurance Cooperative in Europe (AMICE) ${ }^{14}$ indicated that the European Municipal Insurance Group is a loose network of municipal insurers, most of which are mutuals and also members of AMICE. Further research would be needed into such factors as the political and legislative environments in which other European local authorities operate, the nature of the commercial insurance market and the historical attitude

\footnotetext{
${ }^{10}$ Cabinet Office (2002).

${ }^{11}$ London Centre of Excellence (2007); FRAML (2007).

12 Dept of Communities and Local Government (2006).

${ }^{13}$ Young et al. (1999).

${ }^{14}$ www.insurance-mutuals.org.
} 
towards mutuals and pools, but the general evidence would suggest that the concept has been grasped much more enthusiastically outside of the U.K.

In the U.K., where these types of insurance/risk financing pools have existed, they have been traditionally referred to as mutuals, that is, they are owned and utilised by their members. It is important to bear in mind that issues surrounding intra and ultra vires, that is, acting within the limitations of powers and acting outside those limitations, must be addressed. It would be ultra vires for a local authority to share or accept the risks of another local authority, for example legal liabilities or responsibility for property. However, mutual risk pools do not involve the actual risks themselves being shared; it is the negative financial consequences of these risks coming to fruition that are shared by members of the pool, which appears, based on the Cabinet Office ${ }^{15}$ guidance, to be intra vires.

Although found in all branches of insurance, the origins of U.K. mutuals lie in the life sector and this sector still has some in existence. However, difficulties in accessing fresh capital have favoured demutualisation to obtain a status where share capital can be raised and to release assets or profit to the founding or current members. Mutual insurance companies have no capital stock and are owned by policyholders. The earnings of the company, over and above the payments of the losses, operating expenses and reserves, are the property of the policyholders. The origins of mutual insurance as a form of risk financing in the U.K. go back to the establishment of trade guilds centuries ago. Today, they are usually formed when insurance is either expensive or unobtainable, that is, they are influenced by the underwriting cycle, ${ }^{16}$ with hard market conditions being an ideal breeding ground for risk pooling. Allied to the problems associated with the cyclical "hard-market/soft market", many traditional insurers are demonstrably cautious about new and developing areas of risk and they tend to focus on excluding them rather than thinking about ways to cover them. ${ }^{17}$ When pools are formed to overcome these market problems, the aim is usually to write a specific risk or number of risks, for example employers' liability, rather than to replace the commercial insurance market for all insurance needs. In addition to overcoming availability and affordability problems, there may be more direct benefits from concerted risk mitigation actions, particularly if attitudes are shared by fellow mutual owners. As indicated earlier, the insurance market can be highly problematic and local authorities have experienced many of the market-related problems which would point to risk pooling being a creditable financing mechanism.

There is more than one form of risk pool, and the MMI represented a particular type known as a "Guaranteed Indemnity Mutual" (GIM). GIMs, as conventional insurance companies, are subject to broadly similar legislative and regulatory environments. In the U.K. they would fall within the terms of the key pieces of insurance legislation, the Financial Services Act 1986 and the Financial Services and Markets Act 2000, and would be regulated by the body set up under this legislation, the Financial Services Authority. Arguably, this legal/regulatory responsibility on its

\footnotetext{
${ }^{15}$ Op. cit.

${ }^{16}$ Cummings and Outreville (1987); Winter (1989).

${ }^{17}$ ALARM (2005).
} 
own could render the GIM an unattractive option for some local authorities, more so when the substantial capitalisation requirements are considered.

A second form of risk pooling is one based on the "Captive Insurance Company" (Captives) concept, which has long been used by private sector companies. This type can be defined as being an insurance subsidiary that is wholly owned by a noninsurance parent company and that underwrites only that parent's risks. Although advantageous tax arrangements surrounding captives have diminished in recent years, and the fact that captives can help address many of the market and structural problems associated with conventional insurance, they are often still associated with tax avoidance. Like GIMs, captives are required to meet the capital and solvency arrangements of their domiciles, although these requirements may be less onerous than those of the U.K. There are variations as to the precise form a captive may take, with some being more relevant to local authority structures than others, but it is believed that up to the present time local government has not utilised this form of risk financing. Again the issues surrounding intra and ultra vires, allied to regulatory and solvency requirements and the political acceptability of utilising what are perceived to be "tax havens", may have militated against their use.

A third type of pool is the "Discretionary mutual" (DM). DMs represent a form of insurance that is not legally enforceable, that is, the mutual has the discretion as to whether or not it will pay for losses. In reality, however, the discretion not to pay valid claims is seldom, if ever, exercised. For example, in over 100 years of operation the U.K.'s Medical Protection Society and Dental Protection Organisation have never used their discretion to leave a patient uncompensated. ${ }^{18}$ It is this element of discretion which removes the DM from the legislative and regulatory regime to which GIMs are subject. A number of, in broad terms, public sector DMs exist in the U.K., for example, representing medical practitioners and some universities. It must be recognised, however, that some of the members of these risk pools have not, historically, been subject to the same strict statutory regulation as local authorities.

It could be plausibly hypothesised that the traditional legal status of local authorities, specifically the concerns over acting ultra vires, has acted as a barrier to innovation in risk financing. This, however, has changed with the enactment of The Local Government Acts (LGAs) 2000 and 2003 (affecting England and Wales) and the Local Government in Scotland Act, 2003. ${ }^{19}$ This legislation has been generally interpreted as being more flexible in the approach to local authority powers and their ability to trade and invest.

To summarise so far, the Cabinet Office's apparently strong endorsement of innovations in public sector risk financing, the potential for pools to be a legal option for local authorities, the positive experience from both the U.K. and overseas and the problems of the conventional insurance market would suggest that the feasibility and financial viability of risk pools is worthy of detailed consideration. Indeed developments in London (LAML) and in many English Fire and Rescue Authorities (FRAML) point to a situation where feasibility studies have evolved into full-scale

\footnotetext{
${ }^{18}$ Dental Protection Organisation (2007).

${ }^{19}$ Hood and Young (2005).
} 
pooling arrangements. The following section will explore, firstly, the LAML and, secondly, a Scottish feasibility study which did not evolve into a risk pool. Together they will provide insights into the factors which influence the decision-making process with regard to formation of a pool.

\section{To pool or not to pool}

There are a number of macro and micro differences between local authorities in Scotland and England. For all practical purposes, however, the insurable risks to which they are exposed and the main methods available to finance those risks are substantially the same. That being the case, it is valid to compare and contrast the decisions taken in forming the LAML and those taken to abandon the creation of a pool by 16 Scottish authorities.

\section{The London Authorities Mutual Limited (LAML)}

In 2005, a feasibility study was carried out by 28 London local authorities into the creation of a GIM. The detailed figures are not publicly available, but the LAML assert $^{20}$ that the conclusion was that "a mutual insurance company owned by London authorities could generate significant premium savings and, in the medium term, generate a substantial operating surplus for its members". The LAML commenced business on 1 April 2007, and as a GIM is subject to authorisation and regulation by the FSA. A one-off payment from members, in addition to their premium contribution, was required to meet the capitalisation requirements. As discussed earlier, there are additional burdens on GIMs when compared to DMs, but the literature from the LAML is silent on why this form of mutual was utilised. The processes behind this decision would be a useful and interesting area for further research.

Although, unsurprisingly, the LAML do not disclose the precise figures that they used in their decision-making process, they do identify a number of key points to support their business case:

- legal opinion confirmed that the mutual was intra vires;

- robust financial modelling of possible losses indicated a significant surplus over the first 5 years of trading;

- concerns over lack of choice in the insurance market place and over premium costs in relation to claims costs;

- premium savings of 15 per cent would be achieved;

- cover would be equal to, or greater than, that available in the conventional market;

- "consortium" purchasing would result in increased leverage with reinsurers;

- S\&P "A" rated reinsurers would provide appropriate protection;

- the mutual would be tax efficient and underwriting profit would be used for the benefit of members.

\footnotetext{
${ }^{20}$ LAML (2007a)
} 
In many respects, therefore, their feasibility study supported the advantages of pools experienced in other countries. In addition, The London Centre of Excellence, ${ }^{21}$ a partnership of public bodies which aims to optimise the governance and operation of London's public sector, claimed that LAML "will provide a much better deal for local government than we have seen to date". Davies ${ }^{22}$ identified that, in addition to achieving better value for money, the catalysts for the creation of the LAML included the Gershon Efficiency Review and central government's Shared Services Agenda. In April 2008 four additional London authorities joined the 10 original subscribing members of LAML, suggesting that the first year experiences of these members had been positive, that the financial position was robust and that the conventional insurance market was unwilling, or unable, to match the LAML on price, cover or service levels. Indeed, three members have been identified as having had premium savings of $£ 278,000$ in the first year. ${ }^{23}$ An expectation was formed that, as their current insurance contracts expired, more authorities would move to LAML during 2008 and 2009.

Although LAML were confident of their legal position, having taken advice and been subject to rigorous review by the FSA and the Audit Commission, ${ }^{24}$ one insurance provider, concerned that it was being excluded from the public sector insurance market commenced court action in May 2007 to challenge the existence of such mutuals. ${ }^{25}$ The case was brought by Risk Management Partners Limited, a London-based general managing agency owned by the U.S. company Arthur J. Gallacher and with insurance capacity provided by American International Group. A complaint was brought against one LAML member, the London Borough of Brent, although LAML joined the legal action in support of Brent. The complaint challenged whether Brent, under its statutory powers, had the right to join the mutual insurer LAML, and whether it should have followed European rules that require public sector entities to put large procurement contracts out to open tender. In two separate decisions (delivered in April 2008 and May 2008) the judge upheld Risk Management Partners' complaints, finding that the London Borough of Brent had acted ultra vires. Lord Justice Brunton, who heard the case, said he would focus on the "fundamental difference between ... participation in LAML and normal commercial insurance". By participating in the mutual, Brent was not only buying insurance for itself but also providing liability cover to other members participating in the scheme. Brent had paid a $£ 160,500$ capitalisation charge to LAML, and had taken on potentially unlimited liabilities to cover LAML in the event of future shortfalls.

The judge also found that even if it was intra vires, it was not entitled to disregard the Public Contracts Regulations 2006 which requires contracts of this size to be put to open tender. It is not clear whether LAML would have beaten Risk Management Partners in open tender, but the point is that Brent failed to give them the opportunity to do so. Clearly, in the future such procedural niceties could be observed to the letter

\footnotetext{
${ }^{21}$ The London Centre of Excellence (2007).

${ }^{22}$ Davies (2007).

${ }^{23}$ Municipal Journal (2008).

${ }^{24}$ LAML (2007b).

${ }^{25}$ Municipal Journal (2008).
} 
and LAML given the chance to win in open tender. But the ultra vires issue is a fundamental legal issue to be resolved.

The judge gave leave to appeal and that is where the matter now lies. He also suggested that from particular circumstances of the Brent case it would not necessarily follow that no local authority had the power to participate in the London Authorities Mutual. A final decision by the Appeal Court on whether a local authority has the statutory power to participate in a mutual insurer, and whether local authorities are exempt from the U.K.'s Public Contracts Regulations of 2006 is anticipated before February 2009. At this time, however, the existing judgements on the Brent case provide helpful insights into the issues surrounding local authority mutuals. Next we consider our Scottish case and in our Discussion and Conclusion section we pull together our understanding of the issues gleaned from both.

\section{The Scottish experience}

A feasibility study on the viability of insurance pooling was carried out between April 2003 and January 2005, on behalf of 16 (out of a total of 32) Scottish local authorities. The impetus for the project came from the significant increases in the costs of property insurance since 2001 which had resulted in a combination of higher premiums and increased policy excesses (deductibles). Also, there was recognition that historically the prevailing property insurance market conditions meant there was little effective competition to ZMI in the market, ${ }^{26}$ and so local authorities were unable to evidence the achievement of value for money in the procurement of property insurance. Also, the potential existed for significant upward cost fluctuations (premiums increased by 91 per cent in a 2-year period from 2002) in the insurance market and the subsequent knock-on impact on the resources available to deliver front line services. As a consequence of the substantial price increases being encountered, the CIPFA Scotland Directors of Finance Section set up a sub-group to undertake a feasibility study on the viability of insurance facility options. The study had the main objectives of stabilising the existing volatile market; introducing market competition and customer choice; providing greater predictability and budget certainty and allowing value for money to be evidenced through market competition or peer comparison. The feasibility study was carried out in three phases:

- Phase 1: April to August 2003

- Phase 2: September 2003 to February 2004

- Phase 3: March 2004 to February 2005

\section{Phase 1}

This phase was supported by 16 local authorities and reviewed the options available to local authorities to form a risk-financing vehicle to write their property risks. This initiative was driven by a number of concerns. The current year (2003/2004)

\footnotetext{
${ }^{26}$ Heath Lambert Group (2007).
} 
expenditure of the participants on property insurance was $£ 11.8$ million, which suggested that the total cost of property insurance to Scottish authorities was around $£ 25$ million per annum. In reality, the market was virtually a monopoly, with only one truly active market participant and local authorities having little scope for moving from their existing insurance provider. Also, costs of property insurance had risen steeply. Premiums for property insurance had increased by 67 per cent in 2002 and by 24 per cent in 2003. At the same time, deductibles were increasing significantly for each authority at the relevant renewal time, and had trebled over the 3-year period to an average of $£ 81,900$, with the range for individual authorities being from under $£ 25,000$ to over $£ 100,000$. On the basis of the information gathered and collated on behalf of the participants, it appeared that for $2003 / 2004$ the profit to the insurers on property underwriting was approximately $£ 3.3$ million. Investigations under this phase concluded that insurance pooling was viable and offered the potential for costs savings and greater budget stability.

\section{Phase 2}

This phase considered the best structure for the risk financing vehicle and concluded that the optimum way forward was for the local authorities to establish a risk-pooling vehicle in the form of a limited liability company incorporated in the Isle of Man (ISLA Insurance Company Ltd). The opinion of Senior Counsel was sought which confirmed that Scottish local authorities could enter into such arrangements by virtue of their power to advance well-being. ${ }^{27}$

As well as the legal implications, there were other factors to be considered by the participants. Pre-eminent among these was the question of satisfying Best Value rules, especially on transparency. Best Value provides the statutory basis upon which local authorities plan, review and manage their performance. While there was little doubt that in the medium-to-long term pools can compete financially with traditional insurance procurement, many of the savings associated with pooling may be difficult to quantify. Therefore benefits such as better ownership of risk-related data, the fostering of a better risk management culture and medium-to-long-term cover availability and price stability may not fit well within a Best Value calculation. Additionally, there was the attitude of the insurance market itself, especially when the insurance cycle is in "soft market" conditions. During such conditions insurers are more likely to offer premium reductions and more generous terms and conditions actions in themselves that work against the case for risk pools. When the consideration of risk pooling by local authorities, which is unlikely to remain a secret, is added to the soft market position, it would be expected that the rational behaviour of any commercial organisation, that is, the insurers, would be to make their product even more competitive and attractive. This is likely to lead to further concessions on price and product, which will further undermine the case for risk pooling. While those involved in risk financing will be well aware that soft insurance market conditions are inevitably followed by much harder ones, the short-term savings that authorities can

\footnotetext{
${ }^{27}$ As contained in Part 3 (Sections 20-22) of the Local Government in Scotland Act (2003).
} 
make in a competitive environment may, at best, present a significant obstacle during a period of budgetary constraint. Both financially and politically, therefore, risk pooling may be a difficult concept to "sell" to a local authority during a soft market. Unless, therefore, local authority finance or risk officers who favour risk pooling have a mechanism for quantifying all of its benefits, there would seem to be a strong case for promoting the concept during hard market conditions.

An important part of Phase 2 was a 2005/2006 premium tendering exercise. This involved ISLA competing in open competition against other insurance companies in two stages. Firstly, a consortium tender to cover all of the property risks of the local authority participants, and secondly, tenders to meet the risks of individual authorities.

In the first, consortium stage, only ISLA tendered and its price of $£ 7.5$ million represented a 9 per cent saving on the current 2004/2005 premiums. In the second, individual stage, competition between ISLA and current insurers produced better results with total premium quotes of $£ 7.3$ million, which represented an overall reduction of 11.9 per cent on 2004/2005 premiums. Clearly, one of the main objectives of creating market competition was thus met, with all participants receiving a minimum of two quotes and some attracting more.

\section{Phase 3}

However, within the average reduction in premiums of 11.9 per cent there were considerable variations, with large authorities obtaining reductions of 8-29 per cent, while smaller authorities were faced with increases of 4-13 per cent in their property insurance premiums. It seems clear that insurance companies had introduced selective pricing and had targeted reductions at the larger local authorities to, perhaps, reduce the chances of ISLA's success and destabilise the participants' consensus.

Early in 2005, the participants had to consider the way forward and, in particular, decide whether or not to proceed with ISLA. Owing to the extremely favourable renewal terms offered to four of the larger authorities, the number of potential participants fell to 8 (only 25 per cent of Scottish local authorities) and a loss of critical mass was emerging.

In particular, the attainment of short-term gains by local authorities as their existing insurance providers reacted in a commercial way to the threat of competition was important, although there was a realisation that the sustainability of these gains over the longer term in the absence of real competition was problematic. Not all participants would gain from ISLA and losers would struggle to justify participation in terms of value for money and Best Value. Directors of Finance would also need to reflect carefully on their duty to maintain a sound financial position, as contained in the Local Government (Scotland) Act, 1973. This, once again, reinforces the ease with which competitive, even in the short term, commercially available insurance squares with the lower rung accountability issues identified by Stewart. ${ }^{28}$ 
The project got as far as submitting a bid to the Scottish Executive's Efficient Government fund for $£ 1.5$ million to provide initial capital for the insurance company justified by an annual turnover of $£ 7.5$ million and average profit of $£ 300,000$ per annum. However, sufficient support could not be mustered for the April 2005 start-up and the project did not proceed, ${ }^{29}$ although in the light of the English court's decision on LAML that may have been, at least until the appeal outcome is known, a sensible decision.

\section{Discussion and conclusion}

LAML and the Scottish case have provided us with a wealth of raw material from which to extract the key issues underlying recent attempts to revive the concept of local authority mutuals in the U.K. The Scottish case was weakened by the actions of the commercial insurance market in tendering highly competitive premiums to selected potential members of the ISLA. LAML, although not yet killed off, is in peril on account of legal action by a single commercial insurer challenging its legality. Although we did not consider them in detail in this paper, it may be noted that the LAML court ruling led to immediate suspension of FRAML and to a delay in the launch of CARIG. So at the time of writing this paper (August 2008), it appears that in a contest between the new mutuals and the traditional insurance industry, the latter are coasting to an easy victory. But the key forces at play in this struggle are now certainly very clear. For clarity, we now set these out under a number of sub-headings.

\section{The legislative framework will be clarified}

Firstly, let us deal with the current legal wrangling. It is quite possible that the current legal arguments will be merely a temporary stumble in the revival of local authority mutuals in the U.K. If there are rules regarding a competitive tender process then clearly they must be obeyed and local authorities will be more careful in the future. The ultra/intra vires issue will be resolved one way or another once the Appeal Court issues its judgement. So we will either end up with a supportive legislative framework or we will not. Only time will tell.

\section{Evidence that mutuals can deliver attractive cost savings}

Notwithstanding the subsequent legal challenge from RMP, the formation of the LAML appears to suggest that there is a sustainable case in the U.K. for innovation, especially in the context of risk pooling. Greater primary research would be needed with the LAML to examine, in depth, their financial modelling and their decision to form as a GIM. Notwithstanding that, the early evidence would suggest that the pool has delivered on cost savings and is attractive to authorities.

\footnotetext{
${ }^{29}$ Scottish Executive (2006).
} 


\section{New confidence in risk management expertise softens traditional conservatism}

Local authorities are faced with a complex set of risks but have, traditionally, been very conservative in the mechanisms they use to finance these risks - often due to a combination of legal constraints and risk aversion. Many large commercial organisations have developed risk financing strategies that help smooth out relatively predictable fluctuations in property and liability loss experience and mechanisms such as captives are at a high state of development. Simultaneously with these private sector developments, other countries have indeed seen advancements in risk pooling as an effective addition to the public sector risk financing armoury. There appears to be no reason why the U.K.'s local authorities cannot do the same. Only recently have we seen U.K. local authorities experimenting with the wide range of less conservative risk financing techniques that are now available and, indeed, used widely in the private sector. ${ }^{30}$

As the level of professionalism of local authority risk managers increases, increased expertise and confidence may have played a part in the recent attempts at the formation of mutuals. The evidence from the Scottish experience, however, would point to an innate conservatism and a continuing reliance on the conventional insurance market and, mainly, on one major insurer in that market. The caution and conservatism of Directors of Finance are understandable and are well grounded in long established custom and practice. It is our contention, however, that there is a lowrisk alternative to this conservatism which, in the medium-to-long term, could prove advantageous to local authorities, that is, greater utilisation of risk pooling by the formation of mutuals. The formation, after apparently rigorous options appraisal of the LAML and the FRAML demonstrate that examples of innovation and balanced risk taking do exist in the local authority sphere.

It may also be the case that some local authorities would see risk pooling as being little different from the MMI, and are conscious of the collapse of that organisation. That would, however, be a flawed view. The MMI, as a mutual, was a form of risk pool, but its precise form and its strategic and operational approach to insurance principles and practice was quite different from that of contemporary risk pooling arrangements.

\section{The legislative framework must take a medium-to-long-term view}

Insurance is a business where success cannot be measured in the short term - certainly not in any single year. Catastrophe risks such as fire and weather, and legal liabilities, are subject to much year-by-year variability and, in the case of legal liabilities, to a long tail before all claims arise and are settled. Local authority mutuals are no different from other insurers in that they must be free to be judged in the medium-tolong term, rather than just any single year. Unless the law allows them this freedom they will most certainly be fatally weakened. The legislative framework under which local authorities operate would require accepting that the value delivered by any mutual cannot be calculated on a single year's experience.

${ }^{30}$ ALARM (2005); London Centre of Excellence (2007). 


\section{Mutual members must take a medium-to-long-term view}

Given that the underwriting cycle is part and parcel of the insurance market, the inevitable outcome of this will be periods of low market capacity and high premiums and vice versa. In a situation of open tender, the cycles of the insurance market will always tend to produce mutual beating premiums from time to time, at least for some of its members. Moreover, it would be naive to imagine that insurers are not capable of deliberately under-pricing as a tactical measure to win new business - with the hope that windfall profits can be reaped in subsequent years.

\section{Insurers can make life difficult for the mutual}

The initiation of court action by an insurer would indicate that the conventional market sees it as an innovation which is challenging their historical supremacy. The rational behaviour of traditional insurers will be, as appeared to have been the case in the Scottish project, to offer short-term incentives to authorities which undermine the financial viability of pooling. In our view, authorities taking this short-term view are missing a longer term opportunity and are, perhaps, placing too much emphasis on lower rung accountability. There is also the danger that consortia explore pooling, satisfy themselves as to its viability and sustainability and then succumb to the shortterm inducements of the insurance companies. This may only succeed in removing pooling from the risk financing agenda for the foreseeable future.

\section{Mutuals and insurers may co-exist happily}

Risk pooling need not be an "all or nothing" venture. There is no reason why local authorities could not form a pool to finance a specific form of risk, for example fire damage to property, and, at the same time, use their preferred method of risk financing, insurance, for all of their other insurable risks. This heuristic approach would allow authorities to benefit from the advantages of risk pooling, gain experience in the organisation and administration of pooling and develop relationships with reinsurers. At the same time, in recognition of any downside risks, their potential liabilities would be limited by the restricted nature of this exploratory venture. If, as the evidence from other domains would suggest, the pool proved to be viable, economical and sustainable, the framework and organisation would then be in place for wider utilisation. Mutuals will also wish to make use of reinsurance for protection against higher layers of losses or on an account, or stop-loss, basis for a specific class of risk.

\section{The same problems as faced by any industry mutual}

It would be wrong to leave the impression that all problems faced by a local authority mutual would come from external forces such as regulation and the insurance industry. They will face the same problems as any "industry" mutual such as those formed by members of the oil or pharmaceutical industries. Industry mutuals, for example, because they are all engaged in the same range of activities, are likely to face 
a concentration of the same types of risk. This may lead to claims from many members if specific types of loss arise. Industry mutuals work best when members are of a similar "quality" and tensions may arise when some members with excellent risk management and claims record feel they are subsidising less managed authorities. ${ }^{31}$

\section{Summing up}

In terms of a way forward, we recognise that local authorities are fundamentally different from large private sector companies and we are not suggesting that they totally abandon their traditional approach to risk financing and embark on wholesale "alternative" programmes. Given, however, the apparent problems associated with the traditionally cyclical insurance market in terms of capacity and price, we consider that authorities should at least consider the alternatives if they are free to do so following the resolution of the legal issues and the difficulties associated with demonstrating value in any single year.

\section{References}

ALARM (2005) Alternative Risk Financing: Guidance on Alternatives to Traditional Insurance Market Products, Exmouth: Association of Local Authority Risk Managers.

Bovaird, T. and Löffler, E. (2003) Public Management \& Governance, London: Routledge.

Cabinet Office (2002) Risk: Improving Government's Capability to Handle Risk and Uncertainty, London: The Strategy Unit.

Cummings, J.D. and Outreville, J.F. (1987) 'An international analysis of underwriting cycles', Journal of Risk and Insurance 54(2): 246-262.

Davies, M. (2007) Establishment of the London Authorities' Mutual Ltd: A Case Study, London: Centre of Excellence.

De Mey, J. (2003) 'The aftermath of September 11: The impact on and systemic risk to the insurance industry', The Geneva Papers on Risk and Insurance - Issues and Practice 28(1): 65-70.

Dental Protection Organisation (2007) 'Insurance v Indemnity', http:/www.dentalprotection.org/ united_kingdom/VDPs_And_Young_Dentists/Insurance_vs_Indemnity/default.aspx, accessed 6 April 2008.

Department of Communities Local Government (2006) The National Procurement Strategy for Local Government: Two Years On, London: DCLG.

Flynn, N. (2007) Public Sector Management, 5th edn., London: Sage Publications.

Fone, M. and Young, P. (2005) Managing Risks in Public Organisations, Leicester: Perpetuity Press.

FRAML (2007), Insurance mutual now open for business, Fire and Rescue Authorities Mutual Ltd, http:// www.framl.co.uk/view/archives/, accessed 10 April 2008.

Gollier, C. (2001) The Economics of Risk and Time, Cambridge, USA: MIT Press.

Gollier, C. (2003) 'To insure or not to insure?: An insurance puzzle', The Geneva Papers on Risk and Insurance Theory 28(1): 5-24.

Gollier, C. and Pratt, J. (1996) 'Risk vulnerability and the tempering effect of background risk', Econometrica 64: 1109-1124.

Heath Lambert Group (2007) Public Sector, State of the Market 2007: Special Report, London: Heath Lambert Group.

Hood, C. (1991) 'A public management for all Seasons', Public Administration 69(1): 3-19.

Hood, J. and Acc-Nikmehr, N. (2006) 'Local authorities and the financing of the employers' liability risk', Public Money and Management 26(4): 243-250.

\footnotetext{
${ }^{31}$ Punter (2007).
} 
Hood, J. and Young, P. (2005) 'Risk financing in UK local authorities: Is there a case for risk pooling?' International Journal of Public Sector Management 18: 565-578.

LAML (2007a) 'The Establishment of LAML', http://www.londonauthoritiesmutual.co.uk/view/financeand-cover/20070420171217, accessed 16 April 2008.

LAML (2007b) 'LAML Takes on Challenge', http://www.londonauthoritiesmutual.co.uk/view/archive/ 20070807164110 , accessed 16 April 2008.

LASAAC (2005) Accounting for Insurance in Local Authorities in Scotland, Edinburgh: CIPFA, Local Authority (Scotland) Accounts Advisory Committee.

Local Government Act (2000) London: HMSO.

Local Government Act (2003) London: HMSO.

Local Government (Scotland) Act (1973) London: HMSO.

Local Government in Scotland Act (2003) Edinburgh: OQPS.

London Centre of Excellence (2007) 'London Insurance Company Set for Go-Ahead', www.lcpe.gov.uk/ latestnews, accessed 8 March 2008.

Municipal Journal (2008) 'Of Mutual Benefit?', http://www.localgov.co.uk/index.cfm?method=news. detail\&ID $=64979 \& \&$ keywords $=$ of per cent20mutual per cent20benefit. accessed 18 March 2008.

Nawaz, S. and Stein, W. (1998) 'Risk financing 'ART' and the future', Journal of the Society of Fellows, The Chartered Insurance Institute 13(Part 1): 68-81.

Punter, A. (2002) 'Reinventing re/insurance for the twenty-first century', The Geneva Papers on Risk and Insurance, Issues and Practices 27(1): 102-112.

Punter, A. (2007) Risk Financing and Management, 2nd edn., London: IFS School of Finance.

Scottish Executive (2006) 'EGF - Stage 1 - 006 Scottish Local Authority Insurance - Bid', www.scotland. gov.uk/Publications/2006/02/23134928/0, accessed 12 March 2008.

Stewart, J. (1984) 'The role of accounting in public accountability', in A. Hopwood and C. Tomkins (eds) Issues in Public Sector Accounting, London: Philip Alan, pp. 13-34.

Winter, R. (1989) The dynamics of competitive insurance markets, Working paper, Toronto: University of Toronto.

Young, P., Sugimoto, Y. and Yamazaki, H. (1999) 'Pooling in Japan', Public Risk 13(5): 18-21.

\section{About the Authors}

Dr. John Hood is a senior lecturer in Risk Management in the Division of Accountancy, Finance and Risk at Glasgow Caledonian University. He has published widely in the areas of insurance, public sector risk management, risk management in international businesses, public-private partnerships and the risks associated with the outsourcing of services. In addition, he acts as a reviewer for a number of academic journals.

Dr. Bill Stein is a senior lecturer in the Division of Accounting, Finance and Risk at Glasgow Caledonian University. He entered the academic world after a 20 -year career in insurance underwriting and maintains links to the insurance industry. He teaches and researches risk management and insurance and has contributed to several textbooks including those published by the Chartered Insurance Institute, the Chartered Institute of Bankers in Scotland and the Institute of Risk Management.

James McKendrick is a senior lecturer in the Division of Accountancy, Finance and Risk at Glasgow Caledonian University, where he specialises in public sector accounting. He is on the editorial board of the Journal of Finance and Management in the Public Services and acts as a reviewer for Public Money and Management. 